\title{
Divided By a Common Concept? Assessing the Implications of Different Conceptualisations of Hate Crime in the European Union
}

\begin{abstract}
In recent years the European Union has witnessed rising levels of hate crime. However, while there have been a number of legislative and other policy initiatives introduced across the EU to combat such offences, these have developed in a piecemeal and sometimes half-hearted fashion. This article outlines the difficulties evident in theorising hate crime and how these problems have been reflected in the divergent ways that hate crime legislation has developed across the EU. It argues that a human rights-based approach to combating hate crime, endorsed by many EU institutions, has failed to tackle the problem effectively and has resulted in the uneven protection of hate crime victim groups. By utilising an individual rather than group-based human rights approach, the damaging nature and effect of such 'targeted victimisation' upon all hate crime victims can be better understood and addressed.
\end{abstract}

\section{Introduction}

In recent years concern has been growing with regard to the risk of violent victimisation faced by marginalised and disadvantaged social groups within the European Union (EU). At a time of heightened economic difficulties and political uncertainties, these groups have become the subjects of a 'dramatic rise' in certain forms of violence and harassment, or 'hate crime' as it is more widely known. Whether directed against ethnic minority communities, lesbian and gay groups, persons with disabilities or those from Jewish or Roma backgrounds, hate crime is becoming a serious issue for scholars, practitioners and policymakers within the EU (McClintock, 2005; Turner et al., 2009; Pavone, 2010). At the same time however, evidence suggests that different, and often limited, understandings across the EU of the nature of hate crime, are leaving certain minority groups unprotected from harassment and violence (Council of Europe, 2011).

Moreover, it is very difficult to establish the precise levels of hate crime across the EU due to the absence of a shared transnational understanding of what it actually is. Indeed, the development of 'hate crime' as a workable concept in the European Union has been surprisingly lacklustre. By way of contrast, in the United States use of the term 'hate crime' to describe violence targeted against minority communities can be traced back to the civil rights campaigns of the $1960 \mathrm{~s}$, when it was felt 
that there was utility in pooling together the commonalities in the experience of prejudiced victimisation suffered by different minority groups (Levin, 2009). By doing this, these groups could draw strength from their shared victimisation and challenge dominant stereotypes that fuelled much of the harassment they endured.

In many parts of the EU, though, the concept of hate crime has struggled to gain a similarly strong foothold. In the United Kingdom, for instance, it has only really entered the policy and academic arenas during the last decade or so, after two major milestones at the end of the twentieth century - the publication of the Macpherson Report (which examined the police investigation of the racist murder of black teenager Stephen Lawrence in 1993) and the bombing campaign of 'lone wolf' neoNazi David Copeland in London (which killed three people and injured over a hundred others) - gave impetus to new ways of thinking about bias-motivated violence (Chakraborti, 2010). Comparable progress has been less evident in continental Europe though, where there appears to be a much smaller corpus of academic literature relating to hate crime and little evidence of shared understandings of the concept across European Union member states (ODIHR, 2009). The Office for Democratic Institutions and Human Rights (ODIHR), for example, notes that the term 'hate crime' was first used officially by the Organization for Security and Co-operation in Europe (OSCE) only as recently as 2003 (ODIHR, 2010). Since then, the concept has struggled to gain currency in many EU countries (Goodey, 2008). At a time when hate crime appears to be a significant issue across Europe, there is a pressing need for states, statutory and voluntary organisations to grasp the complexities of the phenomenon of hate crime and develop comprehensive policies to address it (ODIHR, 2009a).

This article begins with a necessarily brief outline of key theoretical perspectives of hate crime in order to highlight how some of the conceptual ambiguities and complexities at the heart of these perspectives are mirrored in the diverging interpretations of hate crime adopted across the EU. The article then goes on to discuss the human rights and anti-discrimination frameworks within the EU and how they have helped, in some regards, to challenge the marginalisation of minority groups within the region. However, while some pan-national organisations such as ODIHR have provided a definition of hate crime that could be applicable across nations, to date these efforts do not appear to have developed ideas of hate crime that have genuine meaning in and between states. Indeed, the article will show that a number of nations in the EU have vastly differing understandings of what a hate crime is, who the potential victims are and what type of legislative response is most needed. It will suggest that several factors play a part in creating this confused picture, including historical context, the prioritisation of the needs of some victim groups over others and, worryingly, a lack of commitment in many governmental organisations to tackling hate crime. Whilst a broad human rights framework has been useful in demonstrating the importance of helping those who suffer 
victimisation, it has not been effective enough in fostering a common definition of hate crime that could truly benefit all victim groups. We suggest that the notion of 'targeted victimisation' could play an important role in this process by focusing on the rights of all individuals not to be harassed due to their identity. By moving the focus of the hate crime debate away from discussions of identity groups, and instead towards targeted individuals, it is hoped that the provision of protection for all victims of hate crime, and not just those from certain 'prioritised' groups, will be improved.

\section{Comparative Perspectives of Hate Crime}

\section{Theoretical Conceptualisations}

During its relatively short conceptual lifespan hate crime has become a highly contested term. Uncertainties seem to plague most of its key aspects, including the motivations of offenders and the characteristics of victimisation. For example, much academic discussion has revolved around whether hate crimes are actually motivated by hate, or by less powerful feelings, such as bias or prejudice (Hall, 2005; Lawrence, 2003). Linked to this is the question of whether offenders target potential victims due to their membership of despised 'outgroups', irrespective of who they are as individuals, or whether many offenders, at least to a degree, actually know their victims. Equally, scholars have been divided on whether all communities can be understood as hate crime victim communities or whether this should solely be the 'privilege' of minority groups that have been historically disadvantaged; and even then if we accept the latter premise, which of these disadvantaged groups is 'deserving' of legal protection has been the subject of much conjecture (see, inter alia, Garland, 2011; Mason-Bish, 2010)

Crucially though, there does appear to be scholarly consensus regarding the powerful symbolic nature of hate crimes, in that they transmit a message not just to the immediate victim but to the victim's wider community that their behaviour, cultural norms or presence will not be tolerated: they are thus a method of (re-)emphasising the 'outsider status' of minority groups (Perry, 2009). Accompanying the actual hate act is the inherent threat that further violence will be meted out upon any member of that group if they continue to conduct themselves in ways that the perpetrator deems 'unacceptable'. For commentators such as Walters (2011), the prejudice felt by the perpetrator towards the victim's identity is a key aspect of what constitutes a hate crime. Implicit in such an understanding is that hate crimes do not need to be motivated by hate, but 'merely' by negative feelings held by the offender towards a social group who, in their eyes, has 'outsider' status. This is a pertinent point, as evidence suggests that hate itself is only apparent in a small proportion of hate crimes (McDevitt et al., 2010). Any definitions that insist upon 'hate' being 
present for a crime to be considered a 'hate crime' would therefore exclude a high percentage of those offences, motivated by less powerful emotions like bias or prejudice, which to all intents and purposes, are actually 'hate crimes'. It is for this reason that the term 'bias crime', rather than 'hate crime', has grown in currency among some academics and practitioners in the United States (Roulstone, Thomas and Balderston, 2011).

Interestingly, for authors such as Gerstenfeld (2010) it is the fact that the victim is targeted because of their actual or perceived membership of a social grouping (the 'discriminatory selection' model (Woods, 2008)), rather than the presence of any bias or hatred (the 'group animus' model (ibid)), that is the most significant factor when defining hate crime: it is the attack on their identity that sets these acts apart. Implicit in this argument is that these are 'stranger danger' offences, in which the victim could, in theory, be 'replaced' by someone else from their identity group as it was not them as an individual, but their group identity, that was attacked (Perry, 2001).

Linked to this is the suggestion that hate crimes are more hurtful than 'everyday' crimes lacking the bias motive. As they target cultural, ethnic, religious or sexual identity, for instance, these acts damage feelings of self-worth and security, which can shatter victims' confidence and cause psychological trauma (Herek et al., 2003). Moreover, as they are crimes which send an intimidating message to those of a similar background to the victim, they have a 'ripple effect' that can frighten those in the victim's immediate identity community and beyond (Lawrence, 2003).

For Perry (2009), inter-group conflict between those who hold power within society and those who do not is a fundamental causal aspect of hate crimes. Powerful groups, Perry maintains, intimidate 'subordinate' ones in order to maintain their privileged position within the social hierarchy, as she explains:

... hate crime provides a context in which the perpetrator can reassert his or her hegemonic identity and, at the same time, punish the victim for the individual or collective performance of his or her identity. In other words, hate-motivated violence is used to sustain the privilege of the dominant group and to police the boundaries of the group by reminding the Other of his or her place (Perry, 2009: 72).

Perry (ibid) also suggests that hate crimes mirror prevailing attitudes within society, meaning that 'accepted' media discourse, typified by pervasive heterosexism, for example, can serve to marginalise 'outgroups' like gay populations while reinforcing the dominant position of majority, heterosexual populations. Furthermore, such ideas can also portray 'outgroups' as 'legitimate' objects of hate crime enacted to punish identity performance and reinforce the boundaries of 
hierarchy. Implicit in this argument is the suggestion that dominant groups are the purveyors of hate crimes and weaker ones are the victims.

\section{Perspectives on Hate Crime in the European Union}

Against this background of conceptual confusion have been attempts by some EU transnational organisations to offer workable definitions of hate crime. The Office for Democratic Institutions and Human Rights, for example, suggests that hate crimes have two elements: they must constitute a criminal offence and involve the deliberate targeting of someone because of their membership of a certain group that the perpetrator feels 'some form of bias' against (ODIHR, 2010: 13). Echoing the suggestions above that it is the presence of prejudice which denotes a hate crime, ODIHR offers a broad conception which, unlike Perry's notion, acknowledges that they can be carried out by members of minority groups on those belonging to majority populations. For ODIHR, it is the prejudice behind the offence that is significant: that the perpetrator 'selects the victim based on the victim's membership or perceived membership of a particular group', whether this group is one of Perry's dominant groups or not (ODIHR, 2009: 15 [their emphasis]).

Mirroring Walters's (2011) argument, the same organisation stipulates that this prejudice does not have to manifest itself as hate for the offence to be thought of as a hate crime, nor does it even have to be the primary motive (ODIHR, 2009). For ODIHR (ibid: 16) therefore, hate-related prejudice is 'preconceived negative opinions, intolerance or hatred directed at a particular group [which] must share a common characteristic that is immutable or fundamental, such as "race", ethnicity, language, religion, nationality, sexual orientation'. As we will see below, however, this progressive definition has not filtered down to state level as several EU countries see 'hate' as an inherent component of a hate crime. Other institutions within the EU also do not share ODIHR's ideas. For example, the Council of Europe's cybercrime protocol ${ }^{1}$ (which aims to restrict racism on the Internet) refers to 'hate' in Articles 2, 5 and 6. Yet unfortunately, Paragraph 15 of the Explanatory Memorandum defines 'hate' as 'intense dislike or enmity', something much stronger than the 'bias' element in ODIHR's notion and also something that research, as mentioned earlier, suggests is not evident in the vast majority of 'hate crimes'.

The Scottish Executive (2004: 2) offers a definition of hate crime more in tune with ODIHR's, viewing it as 'crime motivated by malice or ill-will towards a social group', as does the Association of Chief Police Officers (ACPO), in the context of England and Wales, which talks of 'prejudice or hate'

\footnotetext{
1 'Additional Protocol to the Convention on Cybercrime, Concerning the Criminalisation of Acts of Racist and Xenophobic Nature Committed through Computer Systems (2003)'.
} 
needing to be evident (ACPO, 2005: 9) [our emphasis in both examples]. Both contexts allow for an incident to be deemed a hate crime if an element of prejudice informed the offence, even if this motivation was not the central one and was combined with others. In Germany, however, for an incident to be deemed a hate crime then either hate or bias needs to be identified as the primary motive for the offence, as is the case too in Russia (Glet, 2009; McClintock, 2005). In both countries this has meant that offences which would be deemed hate crimes in the British context are not considered so there. In Russia, this has been exacerbated by an alarming tendency for some authorities to be in 'agreement with the prejudices and actions of the suspects' (McClintock, 2005: 30). In Germany, Glet (2009) posits that the classification of the two main subcategories of hate crime, xenophobic and anti-Semitic, as 'politically motivated right-wing crimes' means that hate crimes which do not conform to this notion (such as homophobic or minority on majority racist crimes, or those not committed by far-right extremists) are often misclassified as offences without a bias element. In Sweden, the National Council for Crime Prevention's definition of hate crime states that such offences are 'motivated by fear of, or hostility or hatred' (Klingspor, 2008: 42). The inclusion of 'fear' is interesting as it broadens the criteria of motivating factors to include emotions other than the constrictive 'hate' (ibid).

Of course, it is worth remembering how important history has been in shaping the priorities that nations give to challenging different forms of hate crime. In Austria, Germany and Italy, for instance, events in the twentieth century have inevitably produced a focus upon combating extreme rightwing attitudes and anti-Semitism, while an emphasis on challenging racism in the UK could be attributed to the mass migrations from the Caribbean and south Asia to the UK from the late 1940s onwards. Whatever the case, as Goodey (2008: 17) suggests, 'European legislation and recognition of hate crime is relatively narrow and under-developed' across a number of member states, and it is to a discussion of such legislation that this article now turns.

\section{Hate Crime Legislation in the EU: Compounding, Rather Than Solving, the Problem?}

\section{Background: The Human Rights Framework}

In the context of hate crime, human rights models within the EU tend to include equity of civil rights for all social groups, regardless of status or identity category; the right to be protected from discrimination; the right not to be a victim of a crime that targets one's identity, and the right to expect states to protect citizens from hate crimes (Human Rights Watch, 2011; ODIHR, 2010). A number of interventions within the statutory framework of the EU seek to guarantee these rights. Article 13 of the Treaty of Amsterdam, for instance, aims to prevent discrimination on the grounds 
of certain identity characteristics (race and ethnic origin, religion and belief, gender, sexual orientation, age and disability) while the Lisbon Treaty, along with the legally binding Charter of Fundamental Rights of the European Union, strengthens the framework of non-discrimination legislation. Resolutions and recommendations by the Council of Europe Committee of Ministers and the Parliamentary Assembly also reaffirm the EU's requirement to combat discrimination in its policy and practice (European Agency for Fundamental Rights (FRA), 2010).

The European Convention on Human Rights provides for 'the equal enjoyment of all Convention rights without distinctions based on race, colour, religion, or national or social origin' and obliges states to protect their citizens from injury, attack and assault (Human Rights Watch, 2011: 15). Similarly, the European Court of Human Rights has decreed that states have obligations under the European Convention on Human Rights to investigate whether crimes have a racist motivation, stating that not doing so 'would be to turn a blind eye to the specific nature of acts that are particularly destructive of fundamental rights' (ibid: 16). Also, recent developments have revealed an increasing awareness of the rights of lesbian, gay, bisexual and transgender (LGBT) people in the EU. FRA (2010) notes, for example, that Article 21 of the 'Equality' Chapter of the Charter of Fundamental Rights of the European Union prohibits discrimination on the grounds of sexual orientation. Similarly, the European Court of Human Rights has ruled that states have a requirement to recognise the post-operative gender of transsexuals (Turner et al., 2009).

It is evident, therefore, that a transnational human rights framework offers the possibility for member states to devise their own anti-discrimination and hate crime legislation which enshrines some of these universal ideas of human rights in ways that can protect a wide range of minority groups. However, as demonstrated below, the introduction of such legislation across the EU has been piecemeal, with the obligations set out under broader EU human rights initiatives often ignored as a result of sceptical local attitudes towards hate crime.

\section{The EU Hate Crime 'Umbrella': Full of Holes?}

In November 2008 the European Union Framework Decision on combating racism and xenophobia through criminal law was adopted. The idea behind the Framework was to ensure the 'harmonisation' of 'clear and comprehensive legislation' across the EU regarding xenophobic and racist hate crimes (ODIHR, 2010: 27). Just over a year later the Organization for Security and Cooperation in Europe's Ministerial Council adopted a decision, 'Combating Hate Crimes', which called on all OSCE states (including all EU members) to develop measures to combat the phenomenon, 
including implementing relevant legislation and developing mechanisms to collate reliable statistics (Human Rights Watch, 2011).

Yet, despite these initiatives, a number of different approaches have been evident across the EU with regards to devising and then enforcing hate crime legislation. For example, some countries, such as Belgium and the UK, have introduced laws which state that the offender must have demonstrated some hatred, malice or hostility towards their victim in order to be convicted under that particular legislation ${ }^{2}$. Some of these laws create separate 'racially-aggravated' and 'religiouslyaggravated' offences ${ }^{3}$, although ODIHR (2009a) argues that this is rare among EU states as most have laws which just offer courts the opportunity to enhance the penalty given to a perpetrator ${ }^{4}$. In other cases in the EU, though, it is enough to secure conviction if a causal link is apparent between the offender's actions and the victim's characteristics, regardless of any evidence of bias on the part of the perpetrator ${ }^{5}$ (ODIHR, 2009a).

Compounding the differences in legislation is the lack of consensus (noted above) among academics and practitioners regarding which groups can be defined as hate crime victim groups. This debate extends not just to which minority groups can be included under the hate crime victim 'umbrella' but whether majority groups, as well as minority, can also be incorporated (Chakraborti and Garland, 2009). This difficulty is reflected in the framing of laws within EU member states, with some legislation protecting all groups and others just minorities. In the context of the UK, for instance, anyone can potentially be the victim of a hate crime: thus the law also protects those belonging to majority communities from being victimised by those from minority ones (ACPO, 2005).

Unsurprisingly, this is not something that is consistent across the EU. In the case of Sweden (and with a similarity to Perry's (2009) structural ideas of hate crime discussed above), a member of a majority community cannot be deemed to be the victim of a hate crime if targeted by someone from a minority community, and also, a minority community member cannot be the victim of a hate crime if attacked by somebody from another minority community. As Klingspor (2008: 44) explains:

In the case of an Islamophobic hate crime it has to be established that the victim is, or is perceived by the offender to be Muslim. The offender has to be a non-Muslim ... In the case of an anti-Semitic hate crime it has to be established that the victim is or is perceived to be Jewish.

2 In Belgium, for instance, this is Article 337 of the Penal Code, and in Scotland, Articles 1-2 of the Offences (Aggravated by Prejudice) (Scotland) Act 2009.

3 Sections 29-32 of the UK's Crime and Disorder Act 1998, for example, or Article 196(2) of the Czech Republic's Criminal Code.

4 For instance, the 'Mancino Law' of 1993 in Italy or Articles 33-42 of Belgium's Law of 10 May 2007.

5 See Article 132-76(1) of the French Penal Code or Section 81 (vi) of Denmark's Criminal Code. 
The offender must be non-Jewish. For a homophobic hate crime it has to be established that the victim is or is perceived to be gay. The offender has to be heterosexual.

The contrasting approach between the UK and Sweden is evident in the 'extent of protected groups' dilemma too. For example, of those states that declared to ODIHR which groups they protect under hate crime legislation, 19 had laws with 'ethnicity/nationality' as a protected group, 17 had 'race', and 13 religion (ODIHR, 2010). However, according to FRA (2010a: 13), progress with implementing hate crime legislation relating to sexual orientation has been 'slow and uneven' across the EU, with just 13 member states criminalising incitement to hatred on grounds of sexual orientation, 11 having laws which cite homophobic motivation as an aggravating factor and 12 possessing no laws in which homophobic intent is either a criminal offence or an aggravating factor. Disability is also overlooked, with only seven member states declaring that they included it within their hate crime legislative framework, while only four named transgender status. The marginalisation of such groups from legal protection reflects how they are often excluded from the hate crime debate more broadly (Roulstone et al., 2011).

Lithuania and Slovakia provide notable examples of differing attitudes towards the hate crime legislation 'umbrella'. Slovakia modified its Criminal Code in 2009 to include incitement to national, racial and ethnic hatred. The act of threatening a person or group of people due to their race, nation, nationality, colour of skin, ethnicity, origin or religion, if the threat was the sole motivation, became (in certain specific circumstances) a criminal offence (ODIHR, 2010). This development reveals the focus of the legislation to be rather narrowly aimed at issues of 'race', ethnicity or religion, and then only if the threat was the solitary motivation. This relatively high burden of proof may in itself cause intractable problems for prosecutors and could, in fact, negate the utility of what is already rather limited legislation.

Amendments to Lithuania's Criminal Code, also made in 2009, reveal a more inclusive approach to hate crime legislation. These modifications created provisions for aggravated circumstances to all hate crimes 'on grounds of age, sex, sexual orientation, disability, race, nationality, language, descent, social status, religion, convictions or views' (ibid: 28). This is a broad interpretation as it includes some categories, such as 'language', 'social status', 'conviction' and 'views', which are not evident in the legislation of other nations, like the UK, that are considered to be at the forefront of the development of hate crime legislation in the EU (Chakraborti, 2010).

The inclusion of these categories also broadens the concept of hate crime significantly, moving it away from Perry's (2009) belief that such offences are enacted by the powerful to subordinate the 
disadvantaged, and toward the suggestion that hate crime is really a manifestation of 'targeted victimisation' directed towards someone's perceived 'difference', whether they are part of 'lower' social strata or not. It may be that the victim is from a social group that the perpetrator has negative feelings towards, or the victim may be perceived as being 'vulnerable' by their attacker. It may indeed be a combination of being part of an 'outgroup' and in a vulnerable situation that makes certain people suffer a heightened risk of harassment and violence from those minded to target 'difference'. Whichever it may be, by moving the focus of discussion away from groups and towards an individual level, and by concentrating on notions of risk and vulnerability to harassment, anyone can be the victim of a hate crime; it is the fact that they have been harassed because of their identity that is significant. This notion of 'targeted victimisation' will be returned to shortly.

However, while Lithuania and Slovakia provide contrasting examples of the framing of hate crime laws, the picture is more complex than this. As Goodey (2008) pointedly argues, although legislation in many EU member states may appear comprehensive, there is often a gap between what may be prohibited in law and what states actually punish in practice. The suggestion that this may be due a lack of genuine commitment on the part of some states and agencies will be explored in the next section.

\section{Understanding Differences in Hate Crime Perspectives}

Notwithstanding the differences in historical, political and social context between EU members which inform their hate crime initiatives, there is evidence to suggest that tackling hate crime remains a low priority for some states. Discovering the true extent of the problem is, of course, the first step in combating it, yet, as McClintock (2005: 17) notes, in many EU states government statistical information on hate crime is 'often either unavailable, highly misleading, or years out of date'. For instance, ODIHR reports that Luxembourg and Portugal do not collate any statistics relating to hate crime at all (ODIHR, 2010). Of the 47 participating OSCE states that indicated to the organisation's annual survey that they did collect them, only 31 actually submitted any hate crime data for 2009; 16 failed to do so. However, even the submitted data was problematic for, as ODIHR notes, it was often inconsistent or incomplete, with Italy, France, Spain and Poland neglecting to supply any statistics relating to homophobic or transphobic incidents (ODIHR, 2010).

Indeed, the hate crime categories for which statistics are gathered vary markedly between EU members. For example, Austria, the Czech Republic, Germany, Italy and Sweden have a dedicated 'anti-Semitic' category under which they collate data while the other 22 nations do not. Similarly, just two (Austria and Sweden) have a specific 'crimes against Muslims' category, while only Sweden 
has one for 'anti-Roma' offences (ODIHR, 2010). Not only that, but low priority is often accorded to the accurate collection of such data by the police and other statutory bodies. The Russian authorities have persistently miscategorised hate offences committed by the extreme right as simply 'hooliganism', missing the bias motivation behind such incidents altogether (Laryš and Mareš, 2011). The disparity between the numbers of hate offences recorded by state authorities and those noted by non-governmental organisations (NGOs) can be stark, with the European Monitoring Centre on Racism and Xenophobia citing instances when NGOs in Italy have recorded ten times more hate crimes than have shown up in official annual statistics, and NGOs in Germany have recorded five times as many racist murders than the official figures suggest (cited in McClintock, 2005: 20).

Not surprisingly therefore, the numbers of hate offences collated can vary enormously between states. ODIHR reports that the official number of hate crimes recorded in England and Wales for 2009 was 52,102, by far the highest in the European Union. In Germany, by way of contrast, the number of hate crimes for the same year was just 4,583, while in France it was 3,960 (for 2008), the Czech Republic 265, Italy 142 and Spain a paltry 23 (ODIHR, 2010: 24-26). These figures are startling. At face value, they would suggest that England and Wales have a hate crime problem which dwarfs those of comparable EU states, but what is more likely is that the better mechanisms utilised in England and Wales for collating these statistics are responsible for the high number of recorded incidents. In England and Wales a hate crime is recorded if the victim or any other person feel a criminal offence is 'motivated by prejudice or hate' (ACPO, 2005: 9). This 'victim oriented' approach results in higher numbers of hate crimes being recorded than in Austria, Czech Republic or Germany for instance, where the decision as to whether an offence is deemed a hate crime is made at the discretion of investigating police officers, courts or prosecutions. The current priority given by the police, Ministry of Justice and other bodies in England and Wales to tackling hate crimes have also been significant factors in encouraging more victims to report them.

It is a different picture in other EU countries. In Italy, for example, the government has only recently begun to collate hate crime statistics, and what data it does publish reveals only a partial picture of what is actually happening (Human Rights Watch, 2011). This can set in motion a 'vicious circle' of poor service delivery to hate crime victims, as authorities argue that the problem is not significant enough to allocate further resources and use the low official hate crime figures to justify this stance. This can lead to an increase in a lack of confidence in the police, and a subsequent drop in reporting levels, causing even fewer hate crimes to be officially acknowledged and meagre resources dedicated to combating them.

All too often it appears that the pervading political climate within states can influence the efforts that statutory organisations put into combating hate crime, reflecting Perry's (2009) suggestion that 
hegemonic societal values can create conditions in which hate crimes are tolerated. The haphazard ways in which Italy deals with hate crime occurs, for instance, within the context of its Prime Minister, Silvio Berlusconi, stating in 2009 that Italy should not become a multiethnic country (Human Rights Watch, 2011: 3), while Bleich (2007: 158) notes that state-sponsored initiatives designed to combat hate crime in France 'seem designed more for symbolic ends and for public relations than for practical effect'. The recent introduction of legislation that effectively bans Muslim women from wearing facial covering in that country may also be contributing to an overall climate of Islamophobia in France (Williamson and Khiabany, 2010). FRA (2010a) records that the Czech Republic still employs the alarming practice of 'phallometric testing' upon asylum seekers that are fleeing homophobic persecution, as an 'assessment' of their homosexuality. Such a negative situation is not uncommon within the EU, however, as FRA (2009: 7) outlines:

In some Member States, public authorities have not been able, or willing, to ensure the safety of participants in LGBT demonstrations from attacks by counter-demonstrators. Within the last five years attacks of this kind have occurred in Bulgaria, Czech Republic, Estonia, Hungary, Italy, Latvia, Poland, Romania and Sweden ... In several Member States (Bulgaria, Czech Republic, Cyprus, Hungary, Italy and Malta), calls for improving the rights of LGBT persons have invariably been met with negative responses from some politicians and representatives of religious institutions or groups.

That state authorities in a number of countries 'turn a blind eye' to homophobic victimisation is a cause for concern, as is the negative reaction of some senior political and religious figures to initiatives that champion equal rights for gay people. This situation also reflects the varied attitudes within the European Union towards hate crime in general, with some states taking the issue seriously and recognising a number of different strands of victimisation, while others clearly do not.

\section{Conclusion: Reconceptualising Hate Crime as Targeted Victimisation}

As this article has highlighted, hate crime is an inherently problematic concept. Over the few decades of its existence it has proved controversial and divisive, with its precise meaning elusive and its parameters vague. Although hate crime is now recognised across the EU, there still seems little agreement, either theoretically or practically, regarding its constituent parts. Consistency is scarce among either academics or policymakers regarding whether evidence of hate needs to be present in the commissioning of a hate crime, or whether the lesser emotions of bias or prejudice are sufficient. Similarly, there is scant consensus on whether anyone can be the victim of a hate crime or 
whether that is restricted to members of historically marginalised and disadvantaged minority groups. Even then, there is much debate surrounding which minority groups should be covered by relevant legislation, with some countries, such as Austria, restricting it to rather narrow boundaries of 'race', religion and ethnicity, while others, like Belgium, expanding the 'umbrella' to include factors such as political conviction, wealth and health.

These differences may be attributable to the fact that some prejudices are regarded as 'acceptable' in some jurisdictions but not so in others. They may also be due to historical factors, with countries such as Germany and Italy understandably placing an emphasis on monitoring right-wing extremism and anti-Semitism. Of course, there is nothing inherently wrong with local histories flavouring a nation's hate crime policy and practice, and this article is certainly not suggesting that there should be rigidly identical laws and policies adopted across all European Union nations. However, with these marked differences in the way that different states define hate crime, collate relevant statistics and prioritise anti-hate crime policies and practice, it is very difficult to gauge the true extent, nature and impact of hate crime across Europe. In some respects the concept of hate crime, rather than uniting EU countries in a common drive against manifestations of bigotry, instead merely highlights the differences in attitudes between them.

Perhaps these differences also underscore the failure of the transnational 'human rights approach' to deliver consistent and meaningful hate crime legislation and policy across the EU. This is not to dismiss the obvious appeal of such an approach: the concept of human rights is universally understood and can help to bring the issue of hate crime to the political fore. It emphasises that everyone has the right to lead their lives free from harassment or abuse due to their identity status and therefore can broaden the boundaries of the definition of a hate crime victim group to include a wider range of minority communities than has traditionally been the case. However, an emphasis on human rights - when shaping hate crime legislation and practice across nations - can also have significant limitations. Most fundamentally, it has failed to facilitate a consistent approach between nations whose hate crime policies vary markedly in terms of their prioritisation, implementation and effectiveness. As illustrated above, a number of EU states do not effectively enforce what hate crime legislation they have, while others do not even collate meaningful hate crime statistics. Often this apparent lack of commitment takes place in political and social climates that are overtly hostile to 'difference', whether this be immigration, Islam or homosexuality.

Perhaps, then, a human rights approach needs to be augmented by one which does not merely stress the right of minority communities to be free from harassment, but which also emphasises the real harm that such hate crime, or targeted victimisation, can have. Such an approach would acknowledge that all vulnerable communities and social groups, irrespective of minority or majority 
status, can be the subject of hate crime, and that this violence can have a devastating impact. Such an emphasis, if embraced by key governmental and state organisations such as the police, as well as voluntary sector organisations and charities, would help to acknowledge the victimisation suffered by groups who are often excluded from the hate crime debate. This would include those suffering with mental health problems, disabilities or drug and alcohol dependency, as well as the homeless, sex workers and people of transgendered status to name but some examples of victims targeted because of their perceived vulnerability or 'difference' (Chakraborti, 2010). Their historical marginalisation from policy and scholarly domains may be due to the fact that hate crime has often been understood through the prism of identity group politics, with some (perhaps those with more powerful campaigning organisations to lobby on their behalf) routinely provided with support and protection as recognised hate crime victim groups, while others with less political capital miss out (Mason-Bish, 2010). This 'victim hierarchy' is reflected within the EU in the uneven provision of legislative protection for victim groups outlined earlier. Through the targeted victimisation framework, the right of any individual not to be harassed because of their identity characteristics is emphasised. It may then be easier for legislators to comprehend that the targeted victimisation of anyone, whatever their majority/minority group status, is of an equal importance to that of those minority groups, such as ethnic minorities, who seem to have been prioritised for hate crime protection in many EU member states.

By doing this, the realities of potential and actual hate crime victimisation would be prioritised and the human rights of all victim groups highlighted, including those who have thus far received little attention. If future EU initiatives were to recognise the damaging effect of targeted victimisation upon a whole range of communities, then meaningful and sustainable progress could be made in tackling hate crime.

\section{References}

Association of Chief Police Officers (ACPO) (2005) Hate Crime: Delivering a Quality Service - Good Practice and Tactical Guidance. London: Home Office Police Standards Unit.

Bleich, E (2007) Hate Crime Policy in Western Europe: Responding to Racist Violence in Britain, Germany, and France. American Behavioral Scientist. 51 (2): 149-165.

Chakraborti, N (2010) Crimes Against the 'Other': Conceptual, Operational and Empirical Challenges for Hate Studies. Journal of Hate Studies. 8 (1): 9-28.

Chakraborti, N and Garland, J (2009) Hate Crime: Impact, Causes and Responses, London: Sage. 
Council of Europe (2011) Discrimination on the Grounds of Sexual Orientation and Gender Identity in Europe, Strasbourg: Council of Europe Publishing.

European Union Agency for Fundamental Rights (FRA) (2010a) Homophobia and Discrimination on Grounds of Sexual Orientation and Gender Identity in the EU Member States. Vienna: FRA.

European Union Agency for Fundamental Rights (FRA) (2010) Lesbian, Gay, Bisexual and Transgender (LGBT) Rights in the European Union. Vienna: FRA.

European Union Agency for Fundamental Rights (FRA) (2009) Hate Speech and Hate Crimes Against LGBT Persons. Vienna: FRA.

Garland, J (2011) Difficulties and Dilemmas in Defining Hate Crime Victimisation. International Review of Victimology. 00: 1-22 (accessed 22 April 2011).

Gerstenfeld, PB (2010) Hate Crimes: Causes, Controls and Controversies ( $2^{\text {nd }}$ edition). Los Angeles: Sage.

Glet, A (2009) The German Hate Crime Concept: An Account of the Classification and Registration of Bias-Motivated Offences and the Implementation of the Hate Crime Model into Germany's Law Enforcement System. Internet Journal of Criminology. 1-20.

Goodey, J (2008) Racist Crime in the European Union: Historical Legacies, Knowledge Gaps, and Policy Development. In: Goodey, J and Aromaa, K (eds) Hate Crime: Papers from the 2006 and 2007 Stockholm Criminology Symposiums. Helsinki: European Institute for Crime Prevention and Control. 16-28.

Hall, N (2005) Hate Crime. Cullompton: Willan.

Herek, GM, Cogan, JC and Roy Gillis, J (2003) Victim Experiences in Hate Crimes Based on Sexual Orientation. In Perry, B (ed) Hate and Bias Crimes: A Reader. London: Routledge. 243-259.

Human Rights Watch (2011) Everyday Intolerance: Racist and Xenophobic Violence in Italy. New York: Human Rights Watch.

Klingspor, K (2008) The Challenges of Collecting Statistical Data in the Field of Hate Crime: The Case of Sweden. In: Goodey, J and Aromaa, K (eds) Hate Crime: Papers from the 2006 and 2007 Stockholm Criminology Symposiums. Helsinki: European Institute for Crime Prevention and Control. 40-55.

Laryš, M and Mareš, M (2011) Right-Wing Extremist Violence in the Russian Federation. Europe-Asia Studies. 63 (1): 129-154. 
Lawrence, FM (2003) Enforcing Bias-Crime Laws Without Bias: Evaluating the DisproportionateEnforcement Critique. Law and Contemporary Problems. 66 (3): 49-69.

Levin, B (2009) The Long Arc of Justice: Race, Violence, and the Emergence of Hate Crimes Law. In: Levin, B (ed.) Hate Crimes Volume 1: Understanding and Defining Hate Crime. Westport, CT: Praeger, 1-22.

Mason Bish, H (2010) Future Challenges for Hate Crime Policy: Lessons from the Past. In: Chakraborti, N (ed.) Hate Crime: Concepts, Policy, Future Directions. Cullompton: Willan. 58-77.

McDevitt, J, Levin, J, Nolan, J and Bennett, S (2010) Hate Crime Offenders. In: Chakraborti, N (ed) Hate Crime: Concepts, Policy, Future Directions. Cullompton: Willan. 124-148.

McClintock, M (2005) Everyday Fears: A Survey of Violent Hate Crimes in Europe and North America. New York: Human Rights First.

Office for Democratic Institutions and Human Rights (ODIHR) (2010) Hate Crimes in the OSCE Region: Incidents and Responses - Annual Report for 2009. Warsaw: OSCE Office for Democratic Institutions and Human Rights.

Office for Democratic Institutions and Human Rights (ODIHR) (2009a) Hate Crime Laws: A Practical Guide. Warsaw: OSCE Office for Democratic Institutions and Human Rights.

Office for Democratic Institutions and Human Rights (ODIHR) (2009) Preventing and Responding to Hate Crimes: A Resource Guide for NGOs in the OSCE Region. Warsaw: OSCE Office for Democratic Institutions and Human Rights.

Pavone, IR (2010) Italian Experiences in Combating Hate Crimes and Hate Speech in Light of Recent Violence By and Against Roma. Acta Juridica Hungarica, 51 (3): 187-197.

Perry, B (2009) The Sociology of Hate: Theoretical Approaches. In: Levin, B (ed) Hate Crimes Volume 1: Understanding and Defining Hate Crime. Westport, CT: Praeger. 55-76.

Perry, B (2001) In the Name of Hate: Understanding Hate Crimes. London: Routledge.

Roulstone, A, Thomas, A and Balderston, S (2011) Between Hate and Vulnerability: Unpacking the British Criminal Justice System's Construction of Disablist Hate Crime. Disability and Society, 26 (3): 351-364.

Scottish Executive (2004) The Working Group on Hate Crime Report. Edinburgh: Scottish Executive.

Turner, L, Whittle, S and Combs, R (2009) Transphobic Hate Crime in the European Union. London: ILGA-Europe and Press for Change. 
Walters, MA (2011) A General Theories of Hate Crime? Strain, Doing Difference and Self Control. Critical Criminology. 00: 1-18 (accessed 24 April 2011).

Williamson, M and Khiabany, G (2010) UK: the Veil and the Politics of Racism. Race and Class. 52 (2): 85-96.

Woods, JB (2008) Taking the 'Hate' Out of Hate Crimes: Applying Unfair Advantage Theory and Opportunistic to Justify the Enhanced Punishment of Opportunistic Bias Crimes. UCLA Law Review. 56 (2): 489-541. 